\title{
Some Observations Regarding the Vibrational Environment in Child Safety Seats
}

\author{
Joseph Giacomin \\ Dept. of Mechanical Engineering \\ The University of Sheffield \\ Mappin Street, Sheffield S1 3JD, UK \\ Tel +44 - 114 - $222-7781 \quad$ Fax +44 - $114-222-7890$ \\ E mail: j.a.giacomin@sheffield.ac.uk
}

Keywords: Vibration, Children, Seat, Comfort

\begin{abstract}
A growing issue in the area of Vehicular Ride Comfort is that of child safety seats. Postural, thermal and vibrational comfort considerations are finding their way into child seat design. This paper makes some observations regarding the current state of child safety seat design, then goes on to present the results of vibration tests performed over two road surfaces using two child seats and two children. The vibration levels measured at the interfaces between the children and their seats were found to be higher than the vibration levels between the driver and the driver's seat. Calculated Power Spectral Densities and Acceleration Transmissibility Functions showed that the vibration transmission characteristics of the coupled system consisting of the automobile seat, child seat and child were different from those of the driver/seat system. Whereas automobile seats normally reduce vibrational disturbances at most frequencies, the child seats tested amplified vibration at most frequencies up to $60 \mathrm{~Hz}$.
\end{abstract}

\section{Introduction}

In the field of vehicular Ride Comfort an important effort has been made in recent years to improve the vibration isolation characteristics of the primary seating systems [6,7]. For what regards child seats, however, most effort to date has been directed towards improving crash safety $[2,3,10]$ since this is their main function. Vibrational comfort is important, however, because children are more and 
more becoming regular passengers in vehicles and because research has shown that vibration is both a source of discomfort $[4,8]$ and a possible risk to human health $[9,14,16]$. The objective of this study was to measure the vibrations in two different child seats and to compare these to the vibrations at the interface between the driver and the automobile seat. Safety and realism considerations suggested that road testing, as opposed to laboratory testing, would be the best approach for the study.

\section{Child Safety Seats}

The heading "child safety seats" includes a number of products which serve to provide a safe environment for children during a crash. Anthropometric changes during early childhood require that a range of products be offered to cover the various sizes of children. A rating system is used to define the age and weight ranges that have been tested safe for each seat. The system in general use in the United Kingdom is the series of stages presented in Table 1.

The current study has concentrated on stage $1 \& 2$ products. The author visited several retailers and visually inspected 25 stage 1, stage 2 or stage $1 \& 2$ seats. Most designs were characterised by a plastic or Styrofoam basket covered in either cotton or polyester cloth. The seats often had a lining under the covering cloth which consisted of polypropylene and almost always included polyester wadding to soften the otherwise hard contact between child and plastic cage. In a few cases there was a supplemental foam cushion between the cage and the wadding material. Three seats had a foam pad which covered both the buttock area and the back area, and a further seat had a small patch of foam covering the region around the head. All seats surveyed indicated compliance with either standard ECE R44/02 or ECE R44/03.

With respect to automobile primary seating systems, the child safety seats presented several possible weaknesses. One weakness was the lack of air holes in the frame to ensure thermal comfort. Automobile seats have ample provision for the movement of air through the seat so as to reduce the overall thermal resistance. Of the 25 child seats inspected most only had small holes in the back area of the cage for the purpose of passing through the seat belt. A second weak point was the lack of adjustable ergonomic features, none of the child seats surveyed provided adjustable surfaces. For what regards vibration, is was noted that only 5 of the 25 seats provided any foam padding. This is interesting considering the significant effort made in recent years to improve the properties of automotive seating foams $[5,11,15]$. A final observation was that the seats surveyed 
were all designed to be fastened to the vehicle by means of the vehicle's belts. This arrangement does not provide rigid coupling between the vehicle and child seat, and free play permits ample excursions of the seat in practice. Attachment systems such as ISOFIX [1] which provide a rigid connection between the child seat and the automobile body would be expected to result in different vibration characteristics than those measured in this study.

\section{Experiment}

The experiment consisted of a series of runs over two road surfaces in the city of Sheffield. The two surfaces selected for the study were a speedbump (Rampton Road) and a pave' surface (Mary Street) as shown in Figure 1. The speedbump provided a low frequency transient input to the vehicle while the pave' (cobblestone) surface provided broadband random input to the vehicle. The pave' surface provided significant vibrational energy at the base of the vehicle seat for all frequencies up to $60 \mathrm{~Hz}$. The vehicle speeds selected for the study were $20 \mathrm{~km} / \mathrm{h}$ when driving over the speedbump and $40 \mathrm{~km} / \mathrm{h}$ over the pave' surface. The surfaces and the speeds closely follow the methods used by the major automobile and seat manufacturers to analyse the Ride Comfort of their products $[6,7]$.

The test automobile was a Rover 214 SLI with 175/SR14 radial tyres. The vehicle had 114,276 km on the odometer, suspensions were efficient, tyres were also efficient and inflated at the factory recommended pressure. During all tests there were two adults in the vehicle, one driving and one running an analogue tape recorder which was mounted on the rear seat. The driver was female, weighed $62.3 \mathrm{~kg}$ and was $1.68 \mathrm{~m}$ in height. The passenger running the recorder was male, weighed $88 \mathrm{~kg}$ and was $1.80 \mathrm{~m}$ in height. During all tests there were also two children in the vehicle occupying two child safety seats. One was George, who is male, and at the time of the tests was $74 \mathrm{~cm}$ in height, weighed $8.6 \mathrm{~kg}$ and was 7 months old. The second child was Anna who was $81 \mathrm{~cm}$ in height, weighed $9.9 \mathrm{~kg}$ and was 28 months old. The child seats were arranged as shown in Figure 2. George occupied a stage 1 seat manufactured by Tomy which was placed on the front passenger seat facing rearwards while Anna occupied a stage 2 seat manufactured by Kwik-Fit which was placed in the middle of the rear passenger seat facing forwards. Both seats were fixed to the vehicle using the automobile's belts as instructed by the documentation accompanying the seats. Neither child seat was new, both had been used for several months prior to the tests.

Five runs over the pave' surface were performed at the fixed speed of $40 \mathrm{~km} / \mathrm{h}$, each producing roughly 25 seconds of data. Seven runs were performed over the speedbump at $20 \mathrm{~km} / \mathrm{h}$, each 
producing roughly 5 seconds of vibration data. The speed was controlled by the driver using the vehicle's instrumentation.

All measured accelerations were relative to the vertical direction of the vehicle which is normally the axis with the highest vibration level in automobiles. The 5 measurement points used are shown in Figure 2. An accelerometer was mounted at the base of each of the front seats to measure the input to the seat. These accelerometers were mounted next to the rear mounting bolt of the outer seat guide and were held to the floor by means of standard accelerometer wax. The remaining three accelerometers were mounted at the interface points between the seats and their respective human occupants. One accelerometer was mounted in a sit-bar [8] which was placed between the driver and the driver's seat while the remaining two accelerometers were mounted in special child-bars designed for the present study. The child-bars (Figure 3) are $50 \mathrm{~mm}$ in diameter and $15 \mathrm{~mm}$ in height and were manufactured from aluminium alloy. The weight of each child bar shell is 38 grams, which becomes 44 grams when the PCB model 336C04 accelerometer is installed. The child-bars were placed under the buttock regions of the children during all tests and were continuously monitored. No accelerometer was placed under the rear seat of the automobile as there is little information available in the relevant literature which establishes what points can be considered as the input to the rear seat.

All five sensors used in the current study were PCB model 336C04 accelerometers whose signals were amplified by a PCB model 483A amplifier rack then recorded using a Kyowa RTP 610 analogue recorder. Both the amplifier rack and the tape recorder were run from an independent $24 \mathrm{~V}$ battery so as to minimise any noise from the automobile's electronic systems.

Data analysis was performed in the laboratory using the Time Data Processing Monitor [TMON] of the LMS CADA-X revision 3.4 software system [13]. The LMS software was run on an HP model 715/64 workstation and a B\&K Type 7517 front-end was used. The data was sampled from the recorder at $256 \mathrm{~Hz}$ and a low pass filter was applied which had a $120 \mathrm{~Hz}$ cut-off frequency

\section{Results}

Figure 4 presents the acceleration time histories from one pass over the speedbump. It can be seen that all signals have strong high frequency components except the interface between the driver and 
the driver's seat. It can also be seen that the accelerations reaching the children were often as high as, or higher than, those at the floor of the automobile. Figure 5 presents acceleration data from the pave' surface. Again the lowest levels were found at the interface between the driver and the driver's seat and again the accelerations at the interface between child and child seat were similar to those on the floor. Tables 2 and 3 summarise all the measured data.

Figure 6 presents the Power Spectral Densities calculated for the seat guides of the two front seats. The PSDs present small differences because the road inputs, the vehicle itself and the seat loadings present asymmetries. It can be seen that the pave' surface produced significant energy up to $60 \mathrm{~Hz}$.

Figure 7 presents the Power Spectral Densities of the acceleration signals at the interfaces between the human occupants and their seats for the pave' surface. The results suggest that the coupled system consisting of the driver and seat provided more isolation than the two systems composed of car seat, child seat and child. Two interesting features were found in the data. The first was the strong vibration amplification at frequencies above $15 \mathrm{~Hz}$ for the front child seat (George). The second feature was the strong resonance of the rear child seat in the neighbourhood of $1.8 \mathrm{~Hz}$.

Figure 8 presents the Acceleration Transmissibility Functions from the floor to the interface at the driver and to the interface of the child in the front seat (George). The transmissibilities were calculated as

$$
\begin{aligned}
H(f) & =\frac{S_{y y}(f)}{S_{x x}(f)} \\
\text { where: } & S_{y y}=\text { output Power Spectral Density } \\
S_{x x} & =\text { input Power Spectral Density }
\end{aligned}
$$

Since an automobile is a noisy test environment, the Transmissibility Functions were also calculated in other ways to check against noise effects. Use of the $\mathrm{H} 1, \mathrm{H} 2$ and $\mathrm{Hv}$ estimators [13] which assume different noise models produced only minor differences with respect to Figure 8. 
Several observations can be made regarding the Transmissibility Functions. The first is that the driver's seat provided good isolation from vibrations since attenuation of 75 percent or more was present for all frequencies above $22 \mathrm{~Hz}$. Attenuation also occurred at the lower frequencies with the exception of the two whole-body resonance frequencies of the human body. The Transmissibility Function was greater than 1 around the two body resonances, from 3 to $5 \mathrm{~Hz}$ and from 9 to $15 \mathrm{~Hz}$ respectively.

The system composed of front passenger seat, child seat and child (George) behaved differently. Vibration was amplified at most frequencies in the range from 0 to $60 \mathrm{~Hz}$ with peak transmissibilities in excess of 400 percent. The only frequency range for which the child seat system was found to provide better isolation than the automobile's primary seating system was in the neighbourhood of the main resonance frequency of the adult human body $(3-5 \mathrm{~Hz})$. The calculated coherence functions were high and thus provide confidence regarding the results. The coherence functions for the curves of Figure 8 were greater than .94 in the region from 1 to $15 \mathrm{~Hz}$ and were in the neighbourhood of .7 for frequencies from 15 to $55 \mathrm{~Hz}$.

\section{Discussion}

Visual inspection of 25 child seats currently on the market suggests that some of the technologies commonly applied to automobile primary seating systems have not yet found their way to child safety seats. Visual observation confirmed that the 25 seats inspected had few postural regulations, no air passages for thermal comfort and little attention to detail in terms of designing for vibrational comfort.

Road testing of two child seats confirmed that the vibration isolation performance of the coupled system composed of car seat, child seat and child was less effective than that of the automobile seat. The vibration levels measured at the interfaces between the two children and their respective seats were high. The calculated Transmissibility Functions showed that amplification of floor vibration was higher than 300 percent at many frequencies in the band from 0 to $60 \mathrm{~Hz}$. A low frequency resonance condition was found for one of the child safety seats (rear seat occupied by Anna) which suggested that there may have been problems due to the lack of coupling between the child seat and the automobile. High frequency amplification was found instead for the front child seat occupied by the other child. The high transmissibility values at frequencies in the neighbourhood of $40 \mathrm{~Hz}$ suggested resonances of the child seat frame and possibly a sub-optimal choice of foam 
since the foam padding is typically assigned the function of attenuating high frequency vibrations in vehicle primary seating and ambulance stretchers [12].

A final comment regarding the test results is that the calculated Transmissibility Function for the child seat differed substantially from what is normally found for adult humans sitting on vehicle seats. This could be caused by the child seat, but the results also suggest that the child had different whole-body resonance frequencies. This would appear logical given the different overall mass and the different mass distribution of the child's body. If differences are confirmed by future research, it will have important implications for standards such as ISO 2631 or BS 6841 which have been developed using data from tests on adults.

\section{Acknowledgements}

The author would like to thank Dr. S. Cafferty for his help with the testing and Mrs. Heather Worden for providing and driving the vehicle. The author would also like to thank George and Anna Worden whose fundamental contribution made the study possible.

\section{References}

[1] Bell, R., Burleigh, D. and Czernakowski, W. 1994, ISOFIX: The potential of a universal vehicle/child restraint interface for misuse reduction and performance enhancement, SAE paper 942220

[2] Bruncassan, F., Cailleret, M.C. and Tarriere, C. 1992, Contribution of biomechanics to child safety in motor vehicles, Annales De Pediatrie, Vol. 39, No. 3, 165-173

[3] Carlsson, G., Norin, H. and Ysander, L. 1991, Rearward-facing child seats, the safest car restraint for children ?, Accid. Anal. Prev., Vol 23, No. 2-3, 175-182

[4] Dupuis, H. and Zerlett, G. 1986, The effects of whole-body vibration, Springer-Verlag, Berlin

[5] Ebe, K. 1994, Effect of density of polyurethane foam on vibration transmission, United Kingdom Informal Group Meeting on Human Response to Vibration, Institute of Naval Medicine, Alverstoke, Gosport, Sept. 19-21

[6] Giacomin, J. and Bracco, R. 1995, An experimental approach for the vibration optimisation of automotive seats, ATA 3rd Int. Conf. on Vehicle Comfort and Ergonomics, Bologna, Italy, March 29-31, 199-208 
[7] Giuliano, F. and Ugo, A. 1992, Experimental assessment of ride comfort: a statistical approach, ATA 2nd International Conference on Vehicle Comfort, Bologna. Italy

[8] Griffin, M.J. 1990, Handbook of human vibration, Academic Press, London

[9] Kelsey, J.L. 1975, An epidemiological study of the relationship between occupations and acute herniated lumbar intervertebral discs, Int. Journal of Epidemiology, Vol. 4, No.3, 197205

[10] Kuhane, C.J. 1986, An evaluation of child passenger safety: the effectiveness and benefits of safety seats, DOT-HS-806-890, National Highway Traffic Safety Administration, Washington D.C.

[11] Leenslag, J.W., Huygens, E. and Tan, A. 1997, Recent advances in the development and characterisation of automotive comfort seating foams, Cellular Polymers, Vol. 16, No. 6, pp. $411-430$

[12] Leyshon, D.R. and Stammers, C.W. 1986, The development and performance of an ambulance stretcher suspension, Proc. Instn. Mech. Engrs., Vol. 200, No. D4, 249-257

[13] LMS International 1992, LMS CADA-X Fourier Monitor Manual, Revision 3.4, LMS International, Leuvan

[14] McLain, R.F. and Weinstein, J.N. 1994, Effects of whole body vibration on dorsal root ganglion neurons, Spine, Vol. 19, No. 13, 1455-1461

[15] Mischer, H.P. 1997, Investigation about the inner dynamic characteristics of polyurethane foam and outside conditions which influence the vibration comfort of car seats, ATA $4^{\text {th }}$ Int. Conf. on Comfort in the Automotive Industry, Bologna, Italy, Oct. 6-7

[16] Necking, L.E., Dahlin, L.B., Friden, J., Lundborg, G., Lundstrom, R. and Thronell, L.E. 1992, Vibration induced muscle injury, The Journal of Hand Surgery, Vol. 17B, No. 3, June, 270-274 


\begin{tabular}{ccc}
\hline Stage & Weight & Approximate Age \\
\hline 1 & $-10 \mathrm{~kg}$ & $0-9$ months \\
$1 \& 2$ & $-18 \mathrm{~kg}$ & $0-4$ years \\
2 & $9-18 \mathrm{~kg}$ & 6 month -4 years \\
$2 \& 3$ & $9-25 \mathrm{~kg}$ & 6 months -6 years \\
3 & $15-36 \mathrm{~kg}$ & 4 years -11 years \\
\hline
\end{tabular}

Table 1) System of stages used to define age and weight limits for child safety seats in the United Kingdom.

\begin{tabular}{ccccc}
\hline & $\begin{array}{c}\text { Minimum } \\
\text { value }\end{array}$ & $\begin{array}{c}\text { Maximum } \\
\text { value }\end{array}$ & RMS value & $\begin{array}{c}\text { Crest } \\
\text { Factor }\end{array}$ \\
\hline Driver seat guide & -.345 & .267 & .112 & 2.73 \\
Driver/seat interface & -.397 & .339 & .126 & 2.92 \\
Passenger seat guide & -.333 & .278 & .116 & 2.64 \\
Front child seat & -.346 & .299 & .115 & 2.79 \\
Rear child seat & -.452 & .396 & .158 & 2.69 \\
\hline
\end{tabular}

Table 2) Summary of the acceleration signals measured on the speedbump surface at $20 \mathrm{~km} / \mathrm{h}$. All values are given in g's. 


\begin{tabular}{ccccc}
\hline & $\begin{array}{c}\text { Minimum } \\
\text { value }\end{array}$ & $\begin{array}{c}\text { Maximum } \\
\text { value }\end{array}$ & RMS value & $\begin{array}{c}\text { Crest } \\
\text { Factor }\end{array}$ \\
\hline Driver seat guide & -.648 & .855 & .165 & 4.55 \\
Driver/seat interface & -.498 & .497 & .122 & 4.07 \\
Passenger seat guide & -.849 & .850 & .177 & 4.79 \\
Front child seat & -.827 & .825 & .168 & 4.93 \\
Rear child seat & -.634 & 1.025 & .153 & 5.42 \\
\hline
\end{tabular}

Table 3) Summary of the acceleration signals measured on the pave' surface at $40 \mathrm{~km} / \mathrm{h}$. All values are given in g's. 

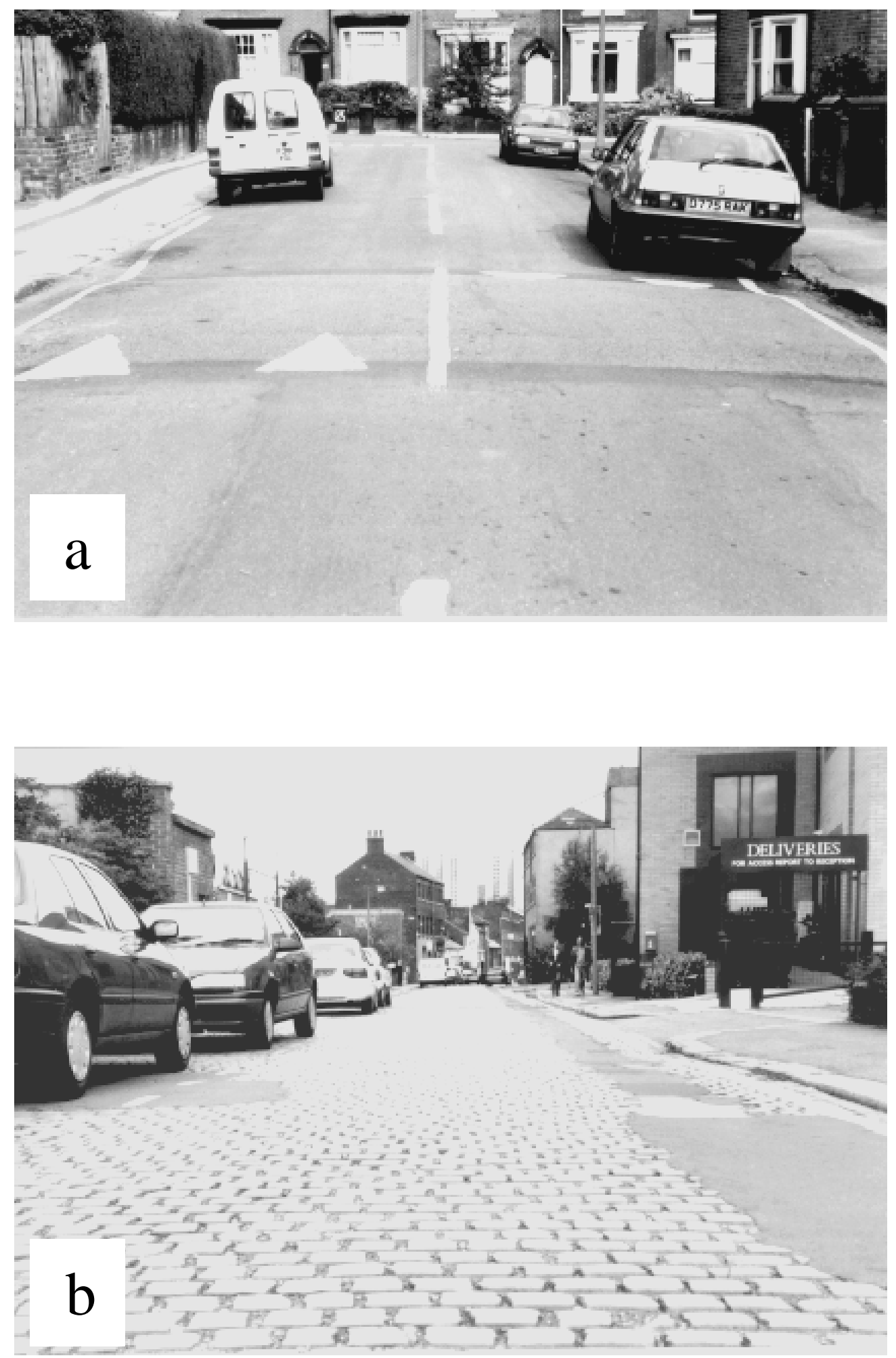

Figure 1) The two road surfaces.

a) Speedbump (Rampton Road)

b) Pave' surface (Mary Street) 


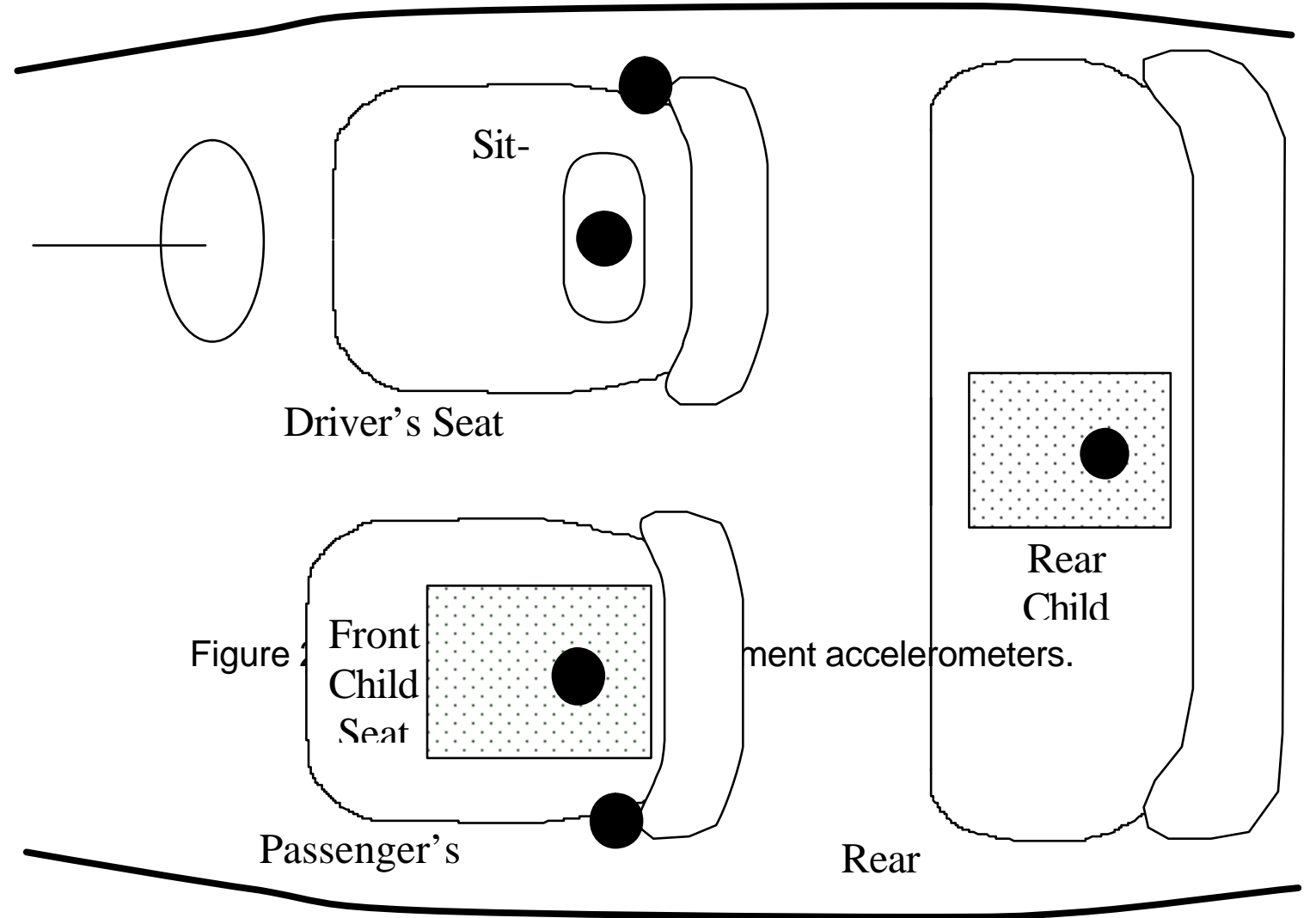

accelerometer location

Figure 2) Location of the measurement accelerometers. 

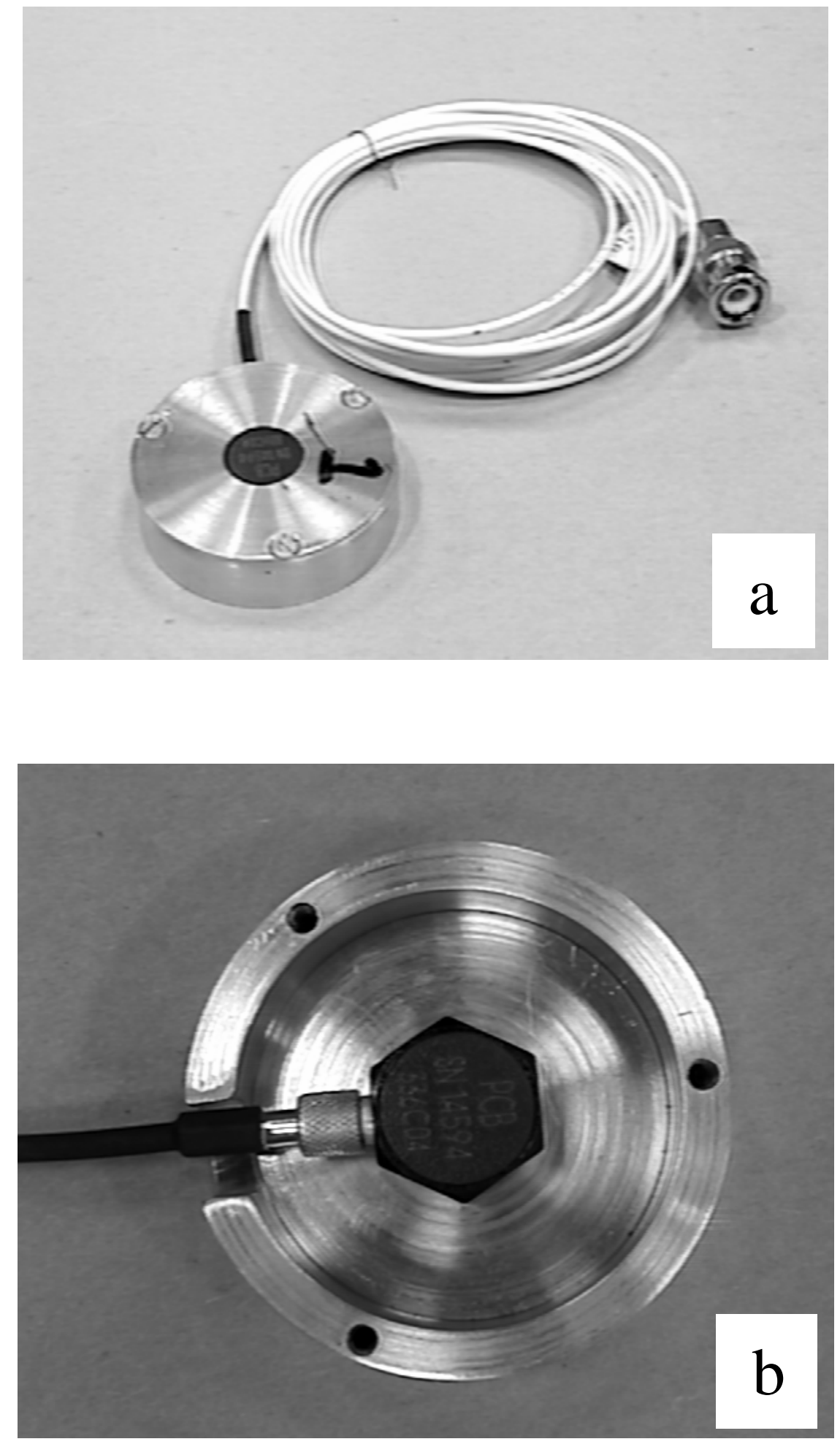

Figure 3) Two views of the child-bar. 

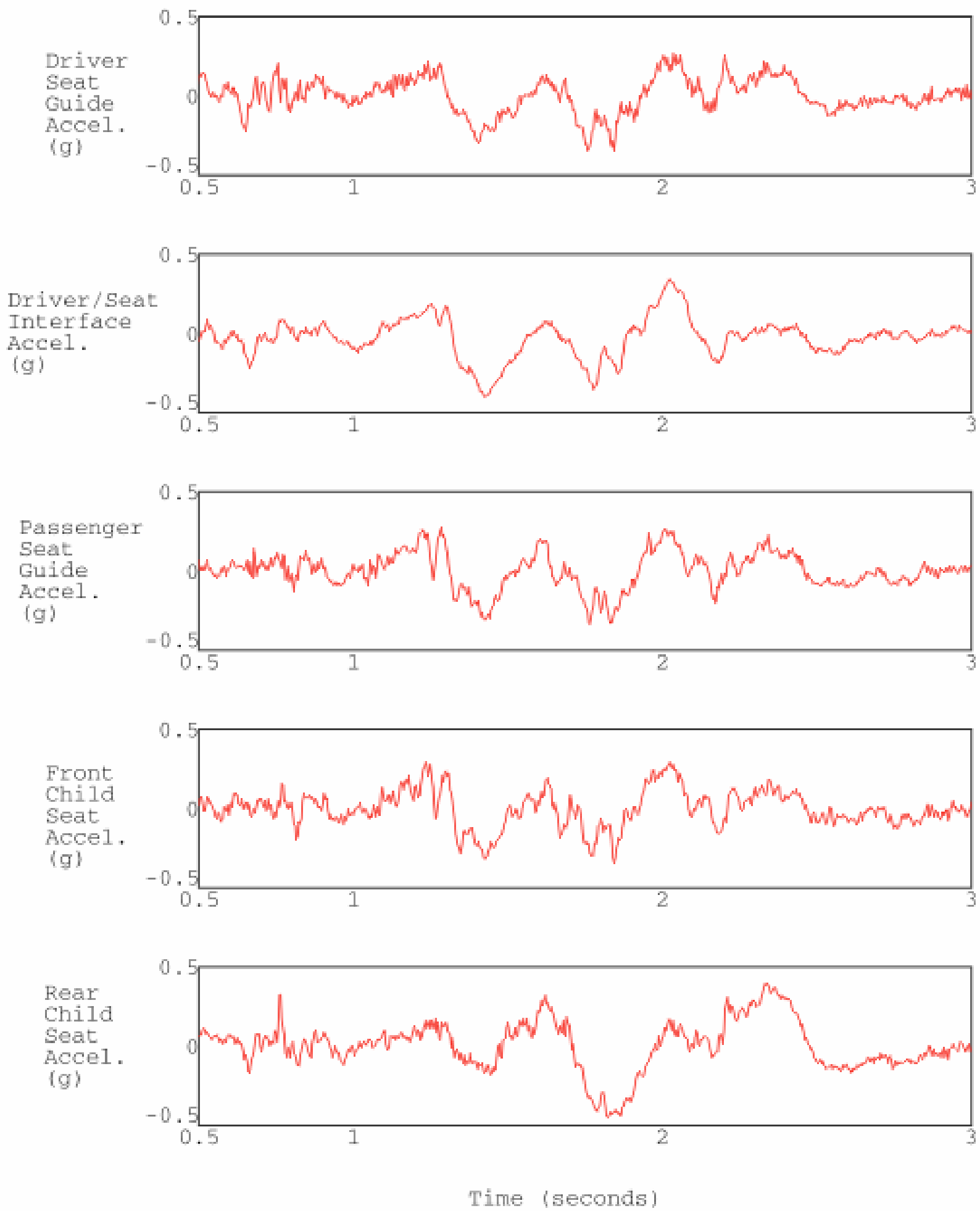

Figure 4) Acceleration time histories measured during one pass over the speedbump at $20 \mathrm{~km} / \mathrm{h}$. 
Driver

Seat

Guide

Accel.

(g)

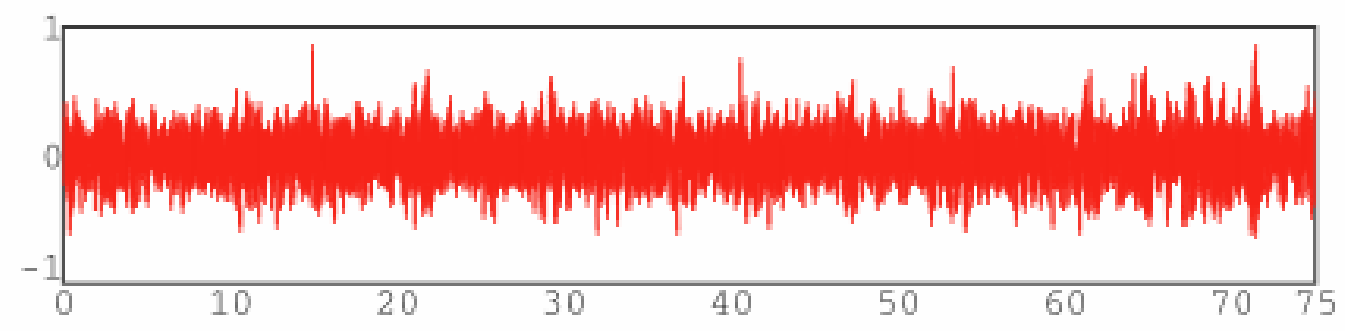

Driver/seat

Interface

Accel.

(g)

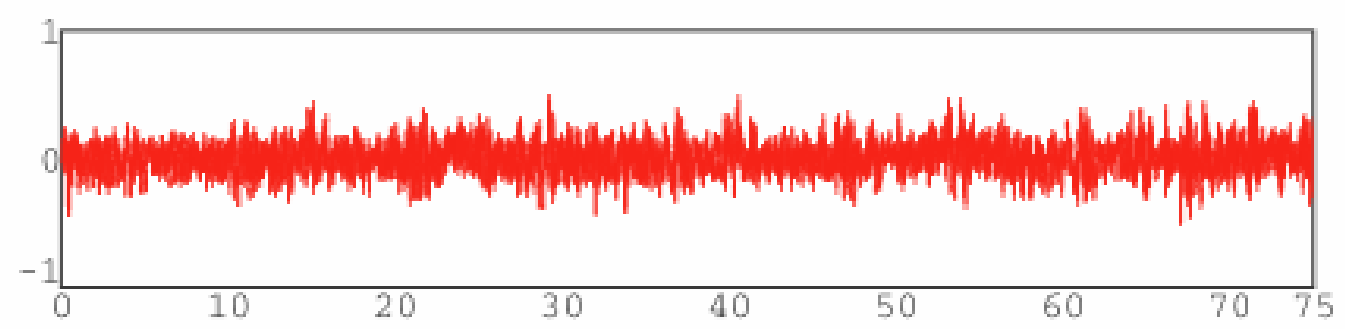

Passenger Seat

Guide

Accel.

(g)

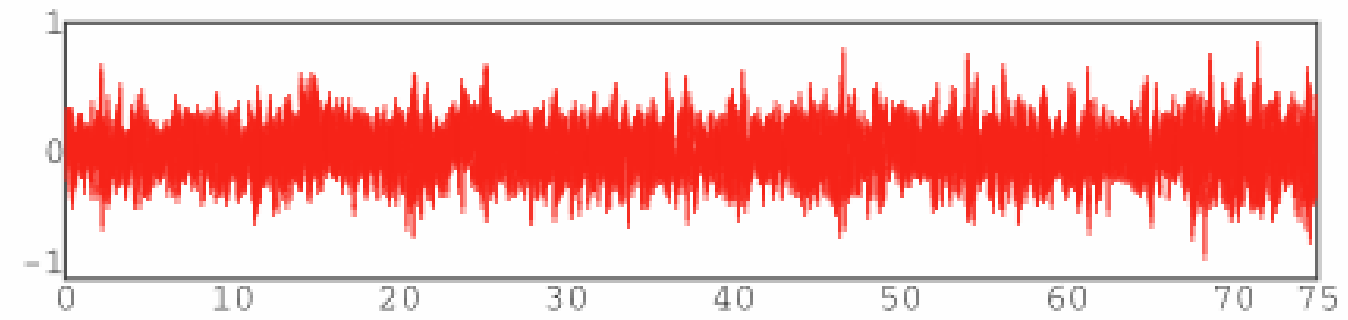

Front

Child

Seat

Accel.

〈g)

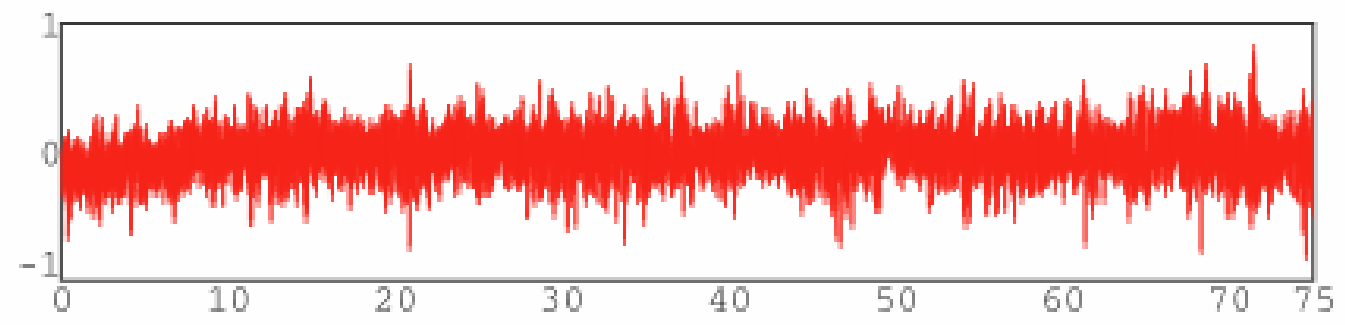

Rear

Child

Seat

Accel.

(g)

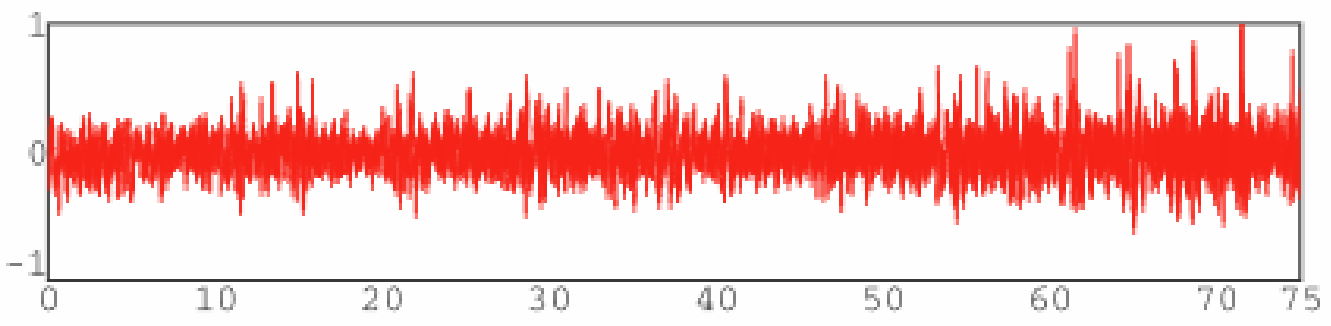

Time (seconds)

Figure 5) Acceleration time histories measured on the pave' surface at $40 \mathrm{~km} / \mathrm{h}$. 


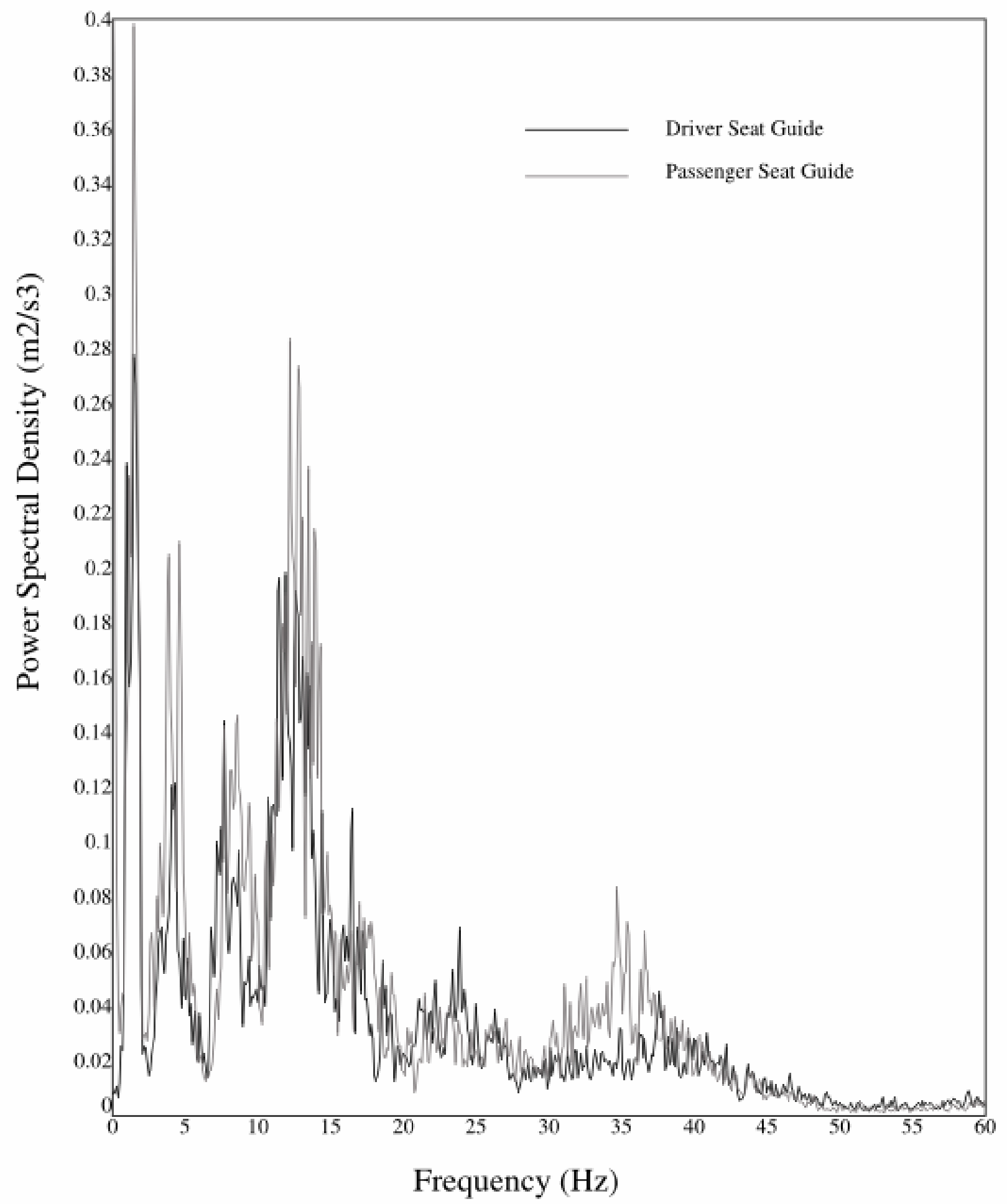

Figure 6) Acceleration Power Spectral Densities at the two seat guides calculated from the acceleration data of the pave' surface. 


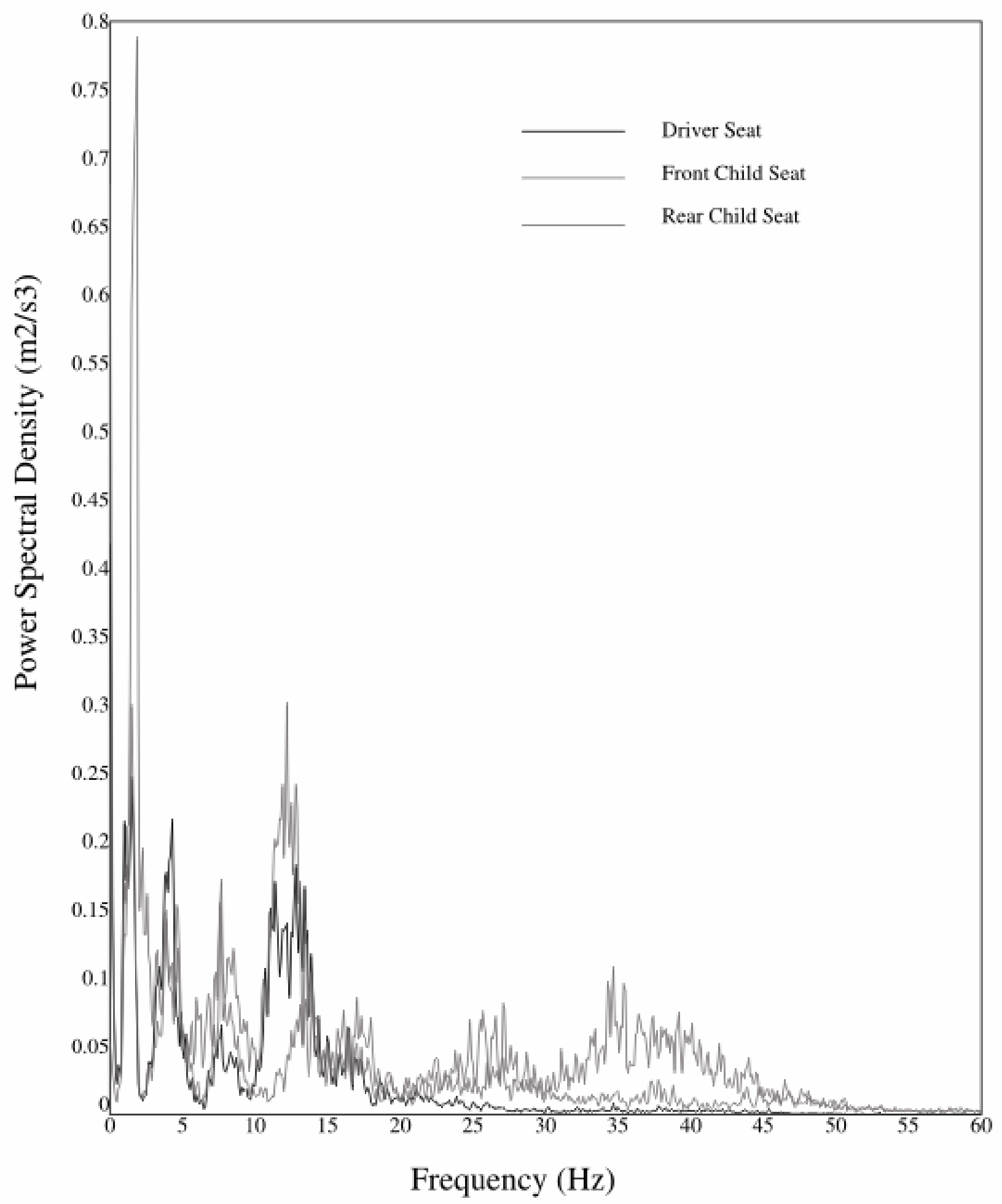

Figure 7) Acceleration Power Spectral Densities at the interface between each vehicle occupant and their respective seat for the pave' surface. 


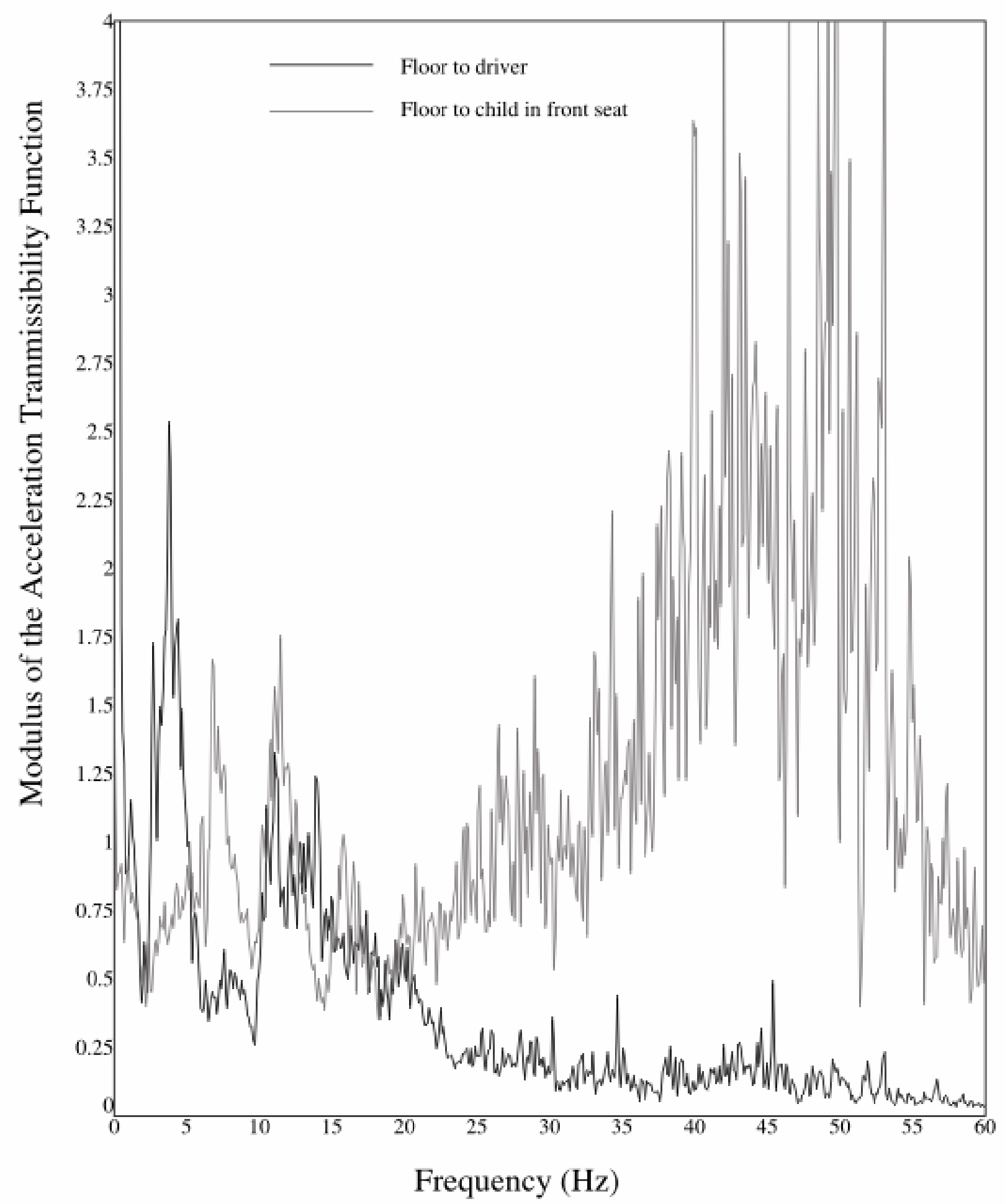

Figure 8) Acceleration Transmissibility Functions calculated from the automobile floor to the driver, and from the automobile floor to the child in the front seat using data from the pave' surface. 